\title{
Coolant pump for compression-ignition aircraft engine
}

The article presents an analysis of the design of cooling liquid pumps for a compression-ignition aircraft engine. A $100 \mathrm{~kW}$ twincharged, two-stroke, liquid-cooled engine has 3 cylinders and 6 opposed-pistons. In the first part of the study, the amount of heat needed to be removed by the cooling system was estimated to obtain the required volumetric flow rate. Then, the design of automotive cooling liquid pumps for compression-ignition engines with a Common Rail power supply system and power of about $100 \mathrm{~kW}$ was analyzed. The aim of the analysis was to select a suitable pump for applications in the aircraft compression-ignition engine. 5 constructions of different shape, diameter and width of the working rotor were selected. The pressure and volume flow rate were determined for a given rotational speed of the pump on a specially built stand. The operation maps of individual pumps were created to select the most efficient types of pumps.

Key words: diesel engine, opposed piston engine, aircraft propulsion system, cooling system, water pump

\section{Introduction}

The main source of heat in internal combustion engines is fuel supplied to the cylinder. The more fuel is supplied to the cylinder, the more heat is obtained from the cylinder as a result of combustion. Part of the heat passes through the walls, heating up the engine. In addition, a significant share is the heat generated by friction. The main source of friction is the crank-piston system, especially the friction between the sleeve and the piston. It reduces engine performance because of its deteriorated mechanical efficiency. At the point of friction, the temperature must not exceed a certain limit due to the thermal strength of the oil film. The engine oil temperature limit is the piston temperature measured at the bottom of the first piston ring duct at the level of $210^{\circ} \mathrm{C}$ [17]. Above this temperature, oil viscosity decreases and the tendency to lock the ring increases.

The main task of the Coolant Pump (CP) is to pump the coolant through the engine channels and the radiator. In most current cooling systems, the temperature of the coolant measured at the engine outlet oscillates between 80 and $90^{\circ} \mathrm{C}$. The boiling point of the refrigerant in the cooling system must not be exceeded due to the possibility of steam plugs and the phenomenon of cavitation. In some engines operating under light and medium loads, in order to reduce fuel consumption, coolant temperature can be increased to about $110^{\circ} \mathrm{C}$ (temperature higher by about $15-20^{\circ} \mathrm{C}$ than the temperature considered suitable for the cooling system). On the other hand, in order to avoid damage to elements of the engine operating under high loads and for the engine to reach its maximum torque and power for the momentary values of rotational speed, it is necessary to quickly reduce coolant temperature by $5-10^{\circ} \mathrm{C}$ below the operating temperature of the cooling system of $90-95^{\circ} \mathrm{C}$.

The authors of the paper [4] analyzed the CP parameters of 1.4 DV4 TED diesel engine from Citroen C3. The maximum temperature increase of the cooling liquid during its flow through the engine block is in the range of $10-15^{\circ} \mathrm{C}$ with the flow rate of the cooling liquid ranging 96-192 $\mathrm{dm}^{3} /$ min. Mean CP efficiency is $20 \%$. When the pump is running at low speeds with the thermostat closed, the total efficiency is reduced to $15 \%$. The main losses of the centrifugal pump are due to secondary flows and changes in the direction of speed after passing through the impeller. Hydraulic power can be lower than the power absorbed by bearings and conventional pump seals. The maximum lifting height of the pump, expressed by the pressure increase between the inlet and outlet at a closed thermostat, is up to $170 \mathrm{kPa}$ [4].

Continuous suction centrifugal pumps are used in engine cooling systems. Their function is to transfer kinetic energy to liquid particles by means of blades of the rotating rotor. The liquid is subjected to a centrifugal force capable of increasing pressure and kinetic energies. The increase of liquid energy depends on the rotor design and its rotational speed.

The classic indirect cooling system of an internal combustion engine consists of a pump (usually centrifugal), which presses cooling liquid into a cooling jacket including channels in the engine block and the head. The liquid is then separated in the thermostat into a short circuit from where it returns to the pump or cooler.

The primary objective of the research on the modification of the cooling system is to reduce fuel consumption and thus $\mathrm{CO}_{2}$. The efficiency of a classic cooling system can be increased by improving components such as the thermostat or pump $[8,18,20]$ and by optimizing the cooling jacket by CFD (Computational Fluid Dynamics) calculations. Major modifications of the cooling system consist mainly in replacing the centrifugal pump SVRP (Sliding Vane Rotary Pump) which has a variable capacity or a coupling disconnecting the pump [19]. There are also used pumps with an electric drive $[1,11,15]$. Such a solution cannot reduce energy consumption over periods of low load. Another popular solution is the use of a regulated thermostat [2] in order to increase the temperature of the cooling liquid in periods of low load and decrease its temperature for heavy loads [13].

\section{Aircraft compression ignition engine $\mathbf{C P}$.}

The CP is designed for the new construction of aircraft engines with compression-ignition and power of $100 \mathrm{~kW}$. 
The liquid-cooled engine has 3 cylinders and 6 opposedpistons. The engine with a capacity of $1.5 \mathrm{dm}^{3}$ is charged by means of a mechanical compressor.

In the planned aircraft diesel oposite pistone engine (OPE), the pump will pump the cooling liquid through the ducts in the engine block and radiator. In the classic design of internal combustion piston engines, the direction of liquid flow is perpendicular to the axis of the individual cylinders. In the analyzed solution, the flow will occur along the axis of additionally finned cylinders (Fig. 1). The direction of flow will affect the resistance of the flowing liquid, the increase in pressure and thus decrease in flow rate. An additional pressure drop will be on the radiator.

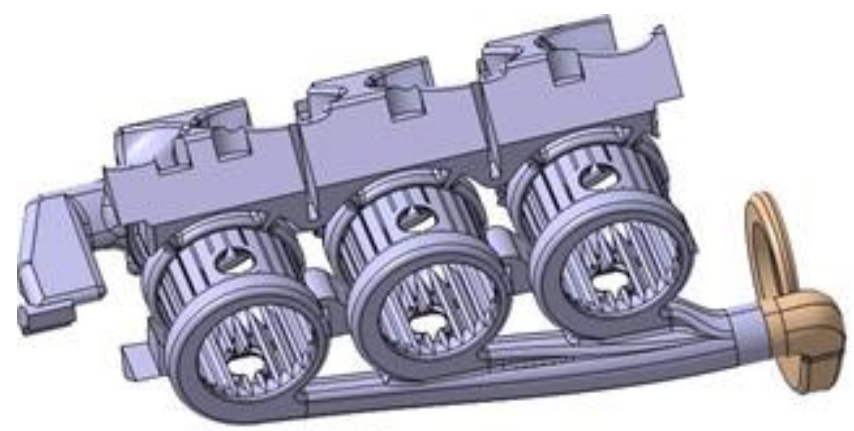

Fig. 1. Channels inside an OPE aircraft engine block with the flow along the axis of the cylinders

The car engine and its cooling system operate in unstable operating conditions. The aim is to shorten the warm-up time of the engine and adjust the pump capacity to the momentary load of the cooling system. Adjustable capacity cooling pumps are introduced. Alternatively, twostate control by disconnecting the drive or blocking the liquid flow in the pump housing. Additional electric pumps are also used to heat the car's interior.

The operation of the aircraft engine is stable. The heating phase takes place on the airport apron and is carried out according to instructions. Then, the engine goes to the operating state in which the aircraft takes off. In this phase, at the beginning, the cooling system absorbs the maximum heat flux from the engine. In addition, there is no airflow forced by aircraft motion. The crankshaft speed of the engine reaches its maximum value at the take-off power.

The CP mechanically driven by the OPE engine should have the lowest possible weight and low power requirement. These parameters will be influenced by the shape of the working rotor and the design of the bearings. The bearing shall be integrated in the drive roller. The main task of the $\mathrm{CP}$ is to pump the coolant through the engine channels and the radiator.

\subsection{Volumetric flow rate requirements}

Heat losses in the head of a classic internal combustion engine construction are significant due to the need to lubricate and cool its working metal elements. The construction of the engine with opposite pistons, whose the combustion chamber is formed by two piston heads and a sleeve, is free of the valve system and the head. The authors of the paper [12] carried out a thermodynamic analysis of an engine with opposed Achates OPS2 pistons. The heat generated is proportional to the volume of the combustion chamber $(\mathrm{V})$, while heat losses are proportional to its surface area (A). In an OPE engine, the $\mathrm{A} / \mathrm{V}$ ratio is almost twice as small as in a classic engine. This results in higher thermal efficiency, which translates into a lower heat flux transmitted to the cooling system. Analysis of the OPE engine by means of the GT-Power software in the article [9] confirms that 59\% of the maximum power of the 3-cylinder engine will be dispersed as heat in the liquid and oil cooling system, which in the case of the designed engine gives a value of $59 \mathrm{~kW}$ $(59 \%$ of $100 \mathrm{~kW})$.

The maximum volumetric flow rate of the pump to the designed aircraft engine was assumed on the basis of simulation tests in the Ansys Fluent at a level of $3 \mathrm{dm}^{3} / \mathrm{s}(180$ $\mathrm{dm}^{3} / \mathrm{min}$ ), with a temperature difference of $5^{\circ} \mathrm{C}$ between the inlet $\left(90^{\circ} \mathrm{C}\right)$ and outlet $\left(95^{\circ} \mathrm{C}\right)$ from the engine block. The pump should provide a constant volumetric flow rate. Its power should be chosen in such a way that there is no significant drop in pressure associated with a reduction in the flow rate of the liquid flow.

In the AVL BOOST software, an OPE engine model has been developed to determine the energy balance of the motor, which is shown graphically in the Sankey diagram in Fig. 2 [10].

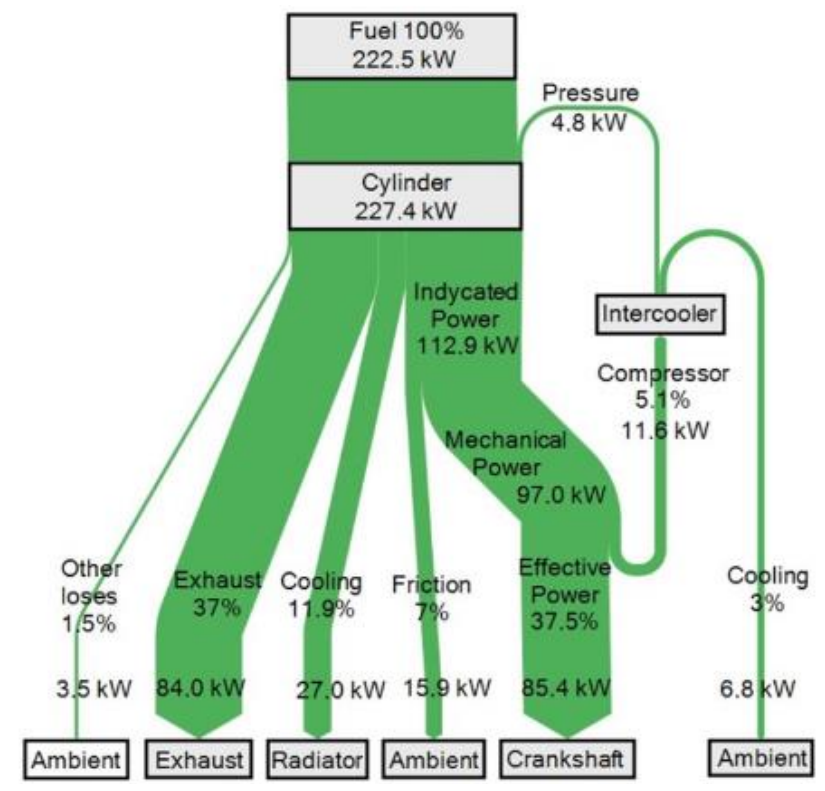

Fig. 2. Sankey's energy balance graph of OPEs aircraft engine with its mechanical compressor - Rotrex C30-64 [10]

It shows that the heat to be dissipated from the engine is the value resulting from the "Cooling" combustion chamber $(27 \mathrm{~kW})$ and friction $(15.9 \mathrm{~kW})$. The friction value also includes maximum power to drive the engine systems: common rail pump $(3 \mathrm{~kW})$, oil pump unit $(0.8 \mathrm{~kW})$, water pump $(0.2 \mathrm{~kW})$, alternator $(0.6 \mathrm{~kW})$. By subtracting the power per unit, the total heat output of the cooling system $\mathrm{E}$ $(38.3 \mathrm{~kW})$ is obtained. On this basis, the pump volumetric flow rate (VFR) can be calculated using the following equation:

$$
\mathrm{Q}=\frac{\mathrm{E}}{\mathrm{C}_{\mathrm{p}} \cdot \Delta \mathrm{T}}
$$


where: $\mathrm{Q}$ - cooling liquid volumetric flow rate through the engine in $\mathrm{dm}^{3} / \mathrm{min}, \mathrm{E}$ - heat dissipated by the cooling system in $\mathrm{kW}, \mathrm{C}_{\mathrm{p}}-$ specific heat of the cooling liquid in $\mathrm{J} / \mathrm{kg} \cdot \mathrm{K}, \Delta \mathrm{T}-$ temperature difference of the cooling liquid between the output/input of the engine block $\left(5^{\circ} \mathrm{C}\right)$.

When using water (specific heat as $4208 \mathrm{~J} / \mathrm{kg} \cdot \mathrm{K}$ at $90^{\circ} \mathrm{C}$ ) as a cooling medium, a volumetric flow rate of 109 $\mathrm{dm}^{3} /$ min should be selected. When using Glysantin ${ }^{\circledR}$ G48 aero coolant mixed 50/50 with water (specific heat as 3412 $\mathrm{J} / \mathrm{kg} \cdot \mathrm{K}$ at $90^{\circ} \mathrm{C}$ ), the pump should have a VFR of 134 $\mathrm{dm}^{3} / \mathrm{min}$.

For comparison, the pump of the Austro Engine AE300 aero cooling system has a VFR of $140 \mathrm{dm}^{3} / \mathrm{min}$. It is a 4 stroke $123 \mathrm{~kW}$ compression-ignition engine powered by the Common Rail system with 4 cylinders and a capacity of about $2 \mathrm{dm}^{3}$.

\subsection{Analysis of automotive coolant pumps}

$\mathrm{CP}$ constructions of modern automotive compressionignition engines with a power of about $100 \mathrm{~kW}$ were analyzed. The aim was to select automotive coolant pumps ideal for aircraft engines, to test them and to select the optimal design for the designed OPE engine. The following pump parameters were specified for particular types of vehicles: number of blades and an impeller diameter as well as the weight of the whole pump. The bolded bars in the diagrams (Figs 3-5) were selected for our bench tests. The speed ratio of the $\mathrm{CP}$ pump/crankshaft is $1: 1$. CP pumps can have a cast iron or aluminium housing (split or a uniform). The split housing has its drive part together with the rotor and cooperates with a water space formed in the engine block. The water space can be formed entirely in the block or partially formed in the pump body. The CP pump can be a separate or integral part of the engine. Such solutions are used in some Ford engine models and in most Japanese designs. The disadvantage of this solution is the large weight of the structure.

Figure 3 shows the rotor diameters of CP pumps in different car engines. According to the analysis, the diameter of the impeller of the CP pump for a diesel engine of 100 $\mathrm{kW}$ has a value in the range of $60-70 \mathrm{~mm}$. The average value is $68 \mathrm{~mm}$.

Figure 4 shows the number of blades of each pump. The pumps have an average of 8 blades located on the impeller. Their shape is straight or curved in one or more planes. The impellers of Citroen and Mercedes pumps are relatively low, so they have 20 and 12 blades at the perimeter, respectively. For comparison, the Mazda rotor is $18 \mathrm{~mm}$ tall and the Citroën $-9 \mathrm{~mm}$.

Figure 5 shows the weight of CP pumps in each vehicle. The average weight of the pumps is $0.93 \mathrm{~kg}$. The lightest $\mathrm{CP}$ pump is the one installed in VW/Skoda cars. The weight is reduced by mounting the bearing and sealing in the drive wheel. Additionally, the working chamber is completely in the engine block. Japanese pumps (Honda, Mazda, Toyota) and Ford cars are heaviest because they are made as separate elements mounted in different engines. These constructions have their working chambers in which the rotor works. The bearing with seals is mounted in the casing of the working chamber.

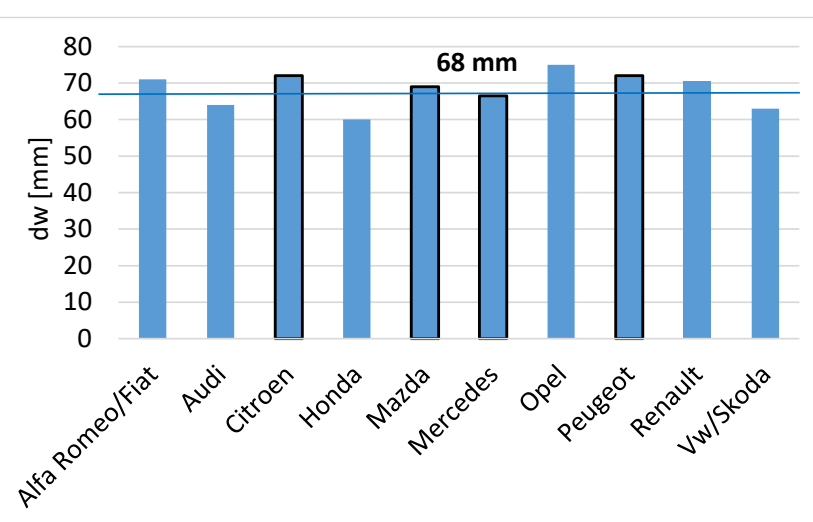

Fig. 3. Impeller diameters of each CP

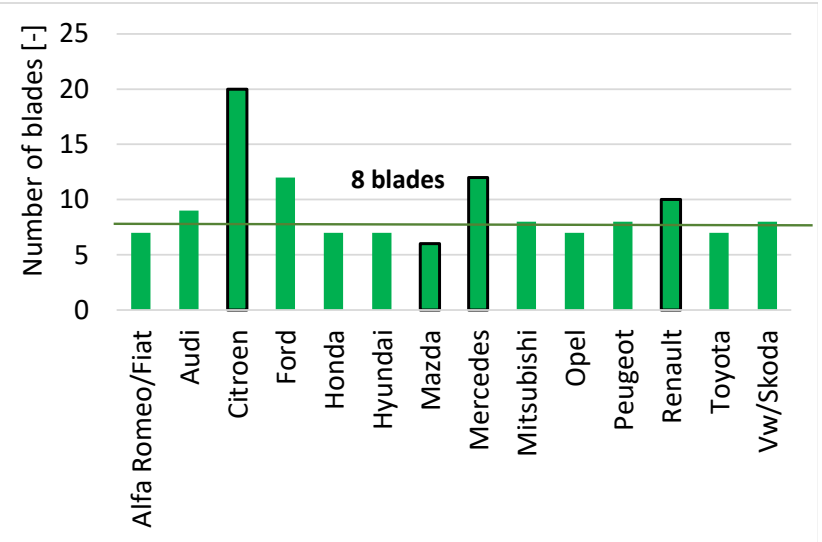

Fig. 4. Number of blades in each CP

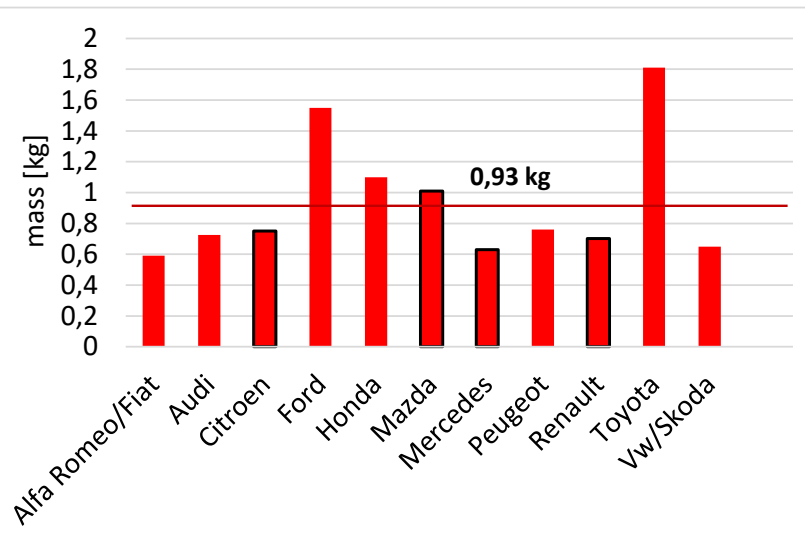

Fig. 5. Weight of each CP

\section{Test stand}

Figure 6 shows a diagram of the CP pump test stand. The Infineon KTY $19-6 \mathrm{M} / \mathrm{Z}$ temperature sensor together with the Wika pressure tensiometer sensor has been installed in the operating chamber of each CP pump. To measure the volumetric flow rate, the BadgerMeter Blancett 1100 turbine flow meter measuring the flow rate from 19 to $190 \mathrm{dm}^{3} / \mathrm{min}$ with an accuracy of $1 \%$ was used. To measure the pump rotational speed, a magneto-inductive sensor Honeywell 1GT101 was used. A 1 1/4 inch volumetric flow control valve was mounted at the outlet from the pump chamber. The internal diameter of the valve is equal to the largest diameter of the outlet channel from among the 
pumps selected for our testing $(50 \mathrm{~mm})$. On the stand, an electric motor of $3 \mathrm{~kW}$ power was installed, selected on the basis of the maximum power of the liquid stream - the product of the maximum output of $180 \mathrm{dm}^{3} / \mathrm{min}$ and the pressure increase of $170 \mathrm{kPa}$ [4].

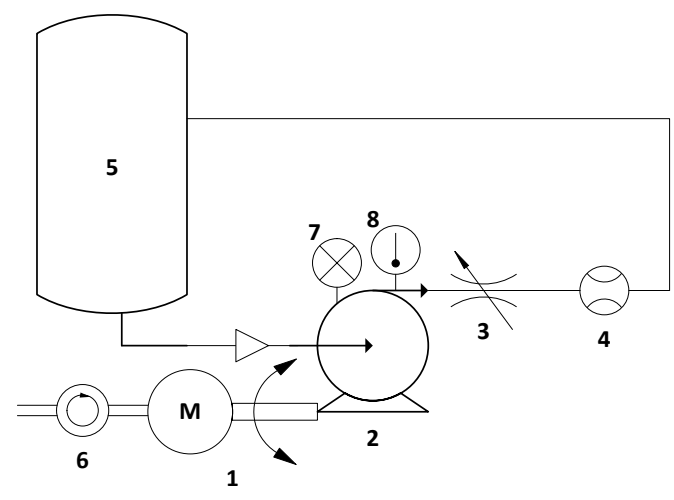

Fig. 6. CP test stand diagram: 1 - electric motor with an inverter, 2 - pump 3 - throttling valve, 4 - flow meter, 5 - tank, 6 - RPM sensor, 7 - pressure sensor, 8 - temperature sensor

Four types of pumps were selected, differing in the rotor design and the shape of the working chamber. Table 1 presents the parameters of the tested CP.

Pumps for our testing were selected in line with the following criteria:

1. the smallest working chamber of the pump in the engine block

2. the smallest possible bearing and so clearance of the drive roller from the working rotor

3. the shape of the pump rotor - during the tests, the pumping efficiency of individual rotor designs will be determined.

Table 1. Parameters of analyzed CP [21]

\begin{tabular}{|c|c|c|c|}
\hline & & \multicolumn{2}{|c|}{ pump rotor } \\
\hline Manufacturer & $\begin{array}{c}\text { mass } \\
{[\mathrm{kg}]}\end{array}$ & $\begin{array}{c}\text { diameter/height of the } \\
\text { working rotor [mm] }\end{array}$ & $\begin{array}{c}\text { number } \\
\text { of blades }\end{array}$ \\
\hline Mazda & 1.01 & $69 / 18$ & 6 \\
\hline Citroen & 0.75 & $72 / 9$ & 20 \\
\hline Mercedes & 0.63 & $66.5 / 11.5$ & 12 \\
\hline Renault & 0.702 & $70.5 / 10$ & 10 \\
\hline & & \\
\hline
\end{tabular}

The reverse-engineering technique reproduces the working chamber of each pump that is located in the engine block. The holes and pockets of the pump impeller and water channels are covered with a thin foil. They were then filled tightly with a plastic material (plasticine) which also covered the surfaces of the block to which the pump seal adheres. The model of the pump working chamber was scanned with a 3D scanner. The mapped geometry was imported into the Catia software which reproduced the internal geometry and designed the housing with holes for the pressure sensor, temperature and inlet and outlet channels. Figure 7 shows a schematic process of mapping the geometry of the pump internal chamber.

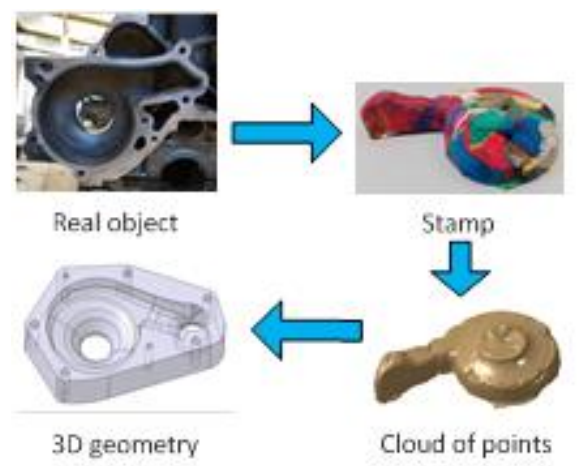

Fig. 7. Diagram of the process of mapping the geometry of the working chamber of the CP Citroen pump

\section{Test conditions}

For the pump speed $\mathrm{n}[\mathrm{rpm}]$ set on the engine inverter, the valve position has been changed using the throttle. The following parameters were read: the volumetric flow rate $\mathrm{Q}$ $\left[\mathrm{dm}^{3} / \mathrm{min}\right]$ of the pump and the increase of the total pressure $\Delta \mathrm{p} 1$ in the system, expressed as:

$$
\Delta \mathrm{p}_{1}=\mathrm{p}_{1}-\mathrm{p}_{\mathrm{s}}
$$

Before the measurements started, the value of static pressure $p_{\mathrm{s}}$ was read which is a result of atmospheric pressure and the height of the water column above the sensor. The tests were carried out for the initial water temperature of $25^{\circ} \mathrm{C}$. The rotational speed of pumps was regulated from $1200 \mathrm{rpm}$ to $7200 \mathrm{rpm}$ every $300 \mathrm{rpm}$. The increasing rotation of the pump rotor increases both the flow and pressure of the liquid, which is a measure of the ability to overcome the resistances occurring in the cooling system. Flow losses occur in straight sections as well as in bends and constrictions when changing diameters. They are also related to the roughness of the walls in the block and in the radiator.

The products of pressure rise $\Delta \mathrm{p} 1$ and mass flow rates $\mathrm{Q}$ determine the stream power expressed in Watts:

$$
\mathrm{P}_{\mathrm{s}}=\mathrm{Q} \cdot \Delta \mathrm{p}_{1}
$$

The power of the stream $\mathrm{P}_{\mathrm{s}}$ defines the work of the flowing liquid per a unit of time. The greater the work is done (the greater the pressure increase at constant flow rate or vice versa) in a unit of time.

\section{Test results}

Figure 8 shows the operating area of the individual pumps. The lower part is the flow characteristic without damping (Fig. 9) at different speeds. The upper part is a characteristic with damping for the rotational speed in the range of 6800-7030 rpm. Each point was obtained by changing the position of the throttling valve. The pressure drops as the volume flow rate increases. The flattest charac- 
teristics is that of the Mercedes pump - the pressure does not drop despite the increase in the volumetric flow rate. Renault and Mercedes pumps have comparable shapes of characteristics. The Citroen pump shows a rapid drop in pressure with an increase in the volumetric flow rate.

All pumps (Fig. 8) show the same pressure drop as the volumetric flow rate increases from approximately 1200 rpm to $7000 \mathrm{rpm}$. The points with the highest flow rate and pressure were obtained at a rotational speed in the range of 6800-7030 rpm. The Citroen pump has a maximum flow rate of $82 \mathrm{dm}^{3} / \mathrm{min}$, Mercedes $172 \mathrm{dm}^{3} / \mathrm{min}$, Renault 150 $\mathrm{dm}^{3} / \mathrm{min}$ and Mazda $164 \mathrm{dm}^{3} / \mathrm{min}$.

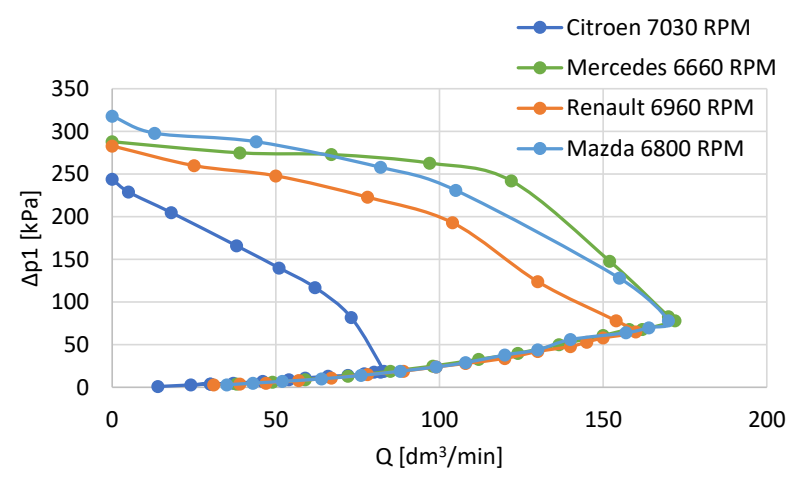

Fig. 8. Working areas of individual CPs - pressure as a function of volumetric flow rate

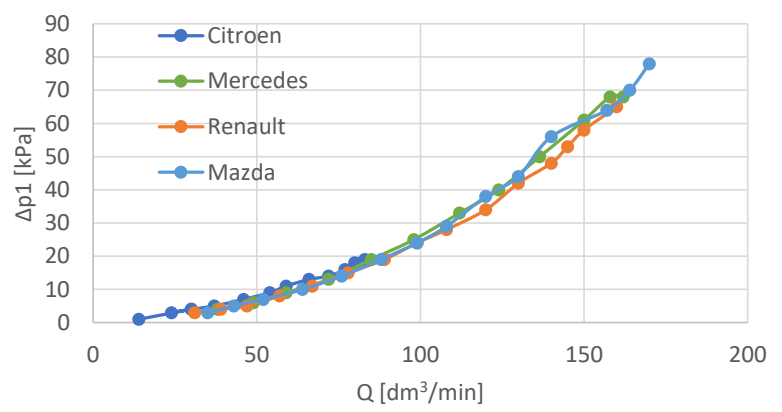

Fig. 9. Characteristics of individual $\mathrm{CP}$ pumps without damping - pressure as a function of volumetric flow rate

Figure 10 shows the full characteristics of the Mercedes Class B 180 CDI pump. The individual curves show the pressure generated by the pump as a function of the flow, expressed in liters per minute. The pressure is constant to approximately $100 \mathrm{dm}^{3} / \mathrm{min}$. As the volumetric flow rate increases (after exceeding $100 \mathrm{dm}^{3} / \mathrm{min}$ ), it starts to decrease. The decrease is larger for higher rotational speeds of the pump impeller.

Figure 11 shows the power of each $\mathrm{CP}$ stream as a function of the rotor speed without damping. It is very clear that the Mercedes pump has the highest stream power. At almost any rotational speed, the products of pressure rise and volumetric flow rate is greater than in the competitive designs. This means that the volumetric flow rate increases with the rotor speed as in all centrifugal pumps.

\section{Summary}

The analysis of the liquid cooling system shows that the following volumetric flow rates are required: $180 \mathrm{dm}^{3} / \mathrm{min}$ (Ansys Fluent), $123 \mathrm{dm}^{3} / \mathrm{min}$ (AVL BOOST), $108 \mathrm{dm}^{3} / \mathrm{min}$
(Austro Engine), given the use of water in the cooling system and a temperature difference of $5^{\circ} \mathrm{C}$. If anti-freezing additives are replaced, the efficiency of the refrigerant is reduced, which means an increase in the required flow rate.

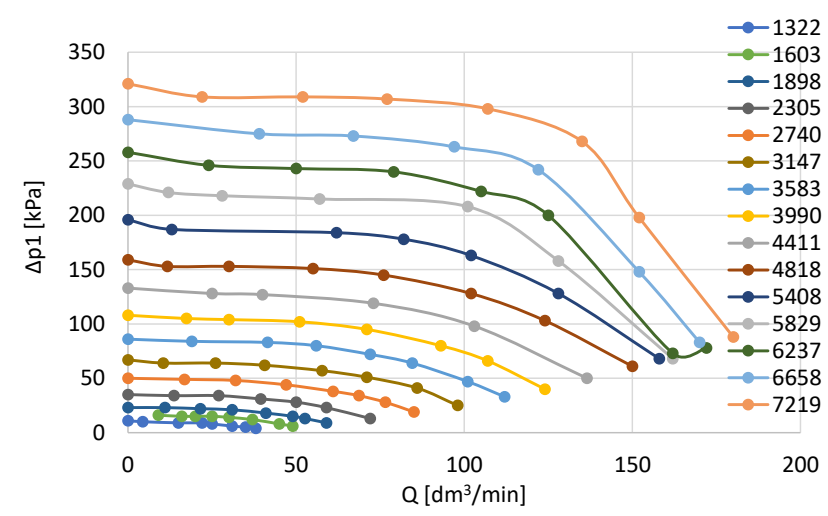

Fig. 10. Mercedes-Class B 180 CDI (damping at each speed) at individual speeds - pressure as a function of volumetric flow rate

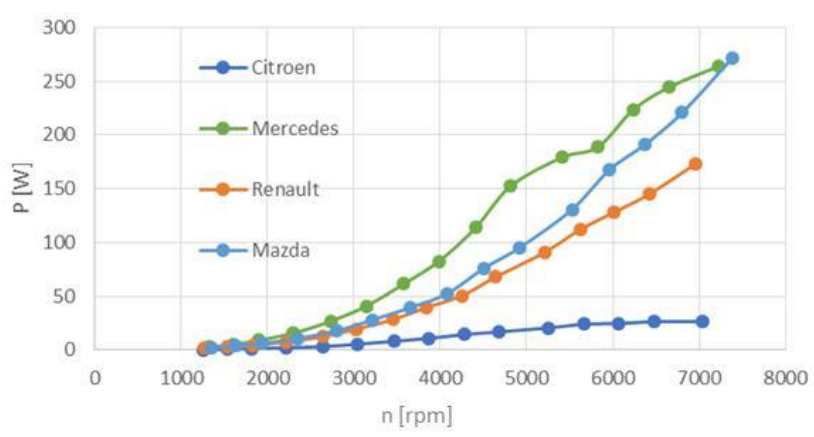

Fig. 11. Stream power of individual CPs as a function of rotor speed without damping

Most of the designs are blade impeller pumps in which part of the working chamber is in the engine block. Bearings and seals in the drive wheel must be used to reduce the weight of the CP pump. Additional weight reduction can be achieved by making the entire operating chamber in the engine block and using the polymer impeller and the aluminium pump casing. The analysis shows that the $100 \mathrm{~kW}$ diesel pump impeller should have a diameter of approximately $68 \mathrm{~mm}$ and 9 blades. The drive is transmitted by means of a belt ridge or a toothed belt that drives the camshaft.

Among the four cooling system pumps tested, the Mercedes pump installed in the B 180 CDI class has the highest performance. At lower rpm, compared to the competitive designs, it achieves a maximum flow rate of $162 \mathrm{dm}^{3} / \mathrm{min}$. Additionally, the pressure does not drop when the flow rate increases as in the other tested constructions. The pump has the highest flow power. Moreover, it is the lightest design $(0.63 \mathrm{~kg})$.

Acknowledgement: This work has been realized in the cooperation with The Construction Office of WSK "PZLKALISZ" S.A." and is part of Grant Agreement No. POIR.01.02.00-00-0002/15 financed by the Polish National Centre for Research and Development. 


\section{Nomenclature}

CP coolant pump

OPE Diesel Opposite Piston Engine

ICE internal combustion engine
CI compression ignition

VFR volumetric flow rate

\section{Bibliography}

[1] CASTIGLIONE, T., BOVA, S., BELLI, M. A model predictive controller for the cooling system of internal combustion engines. 71st Conference of the Italian Thermal Machines Engineering Association. ATI2016, 14-16.

[2] CHASTAIN, J. Internal combustion engine cooling strategies. Clemson University. TigerPrints. 2006. All Theses. Paper 23.

[3] CIPOLlONE, R., BIANCHI, G., DI BATTISTA, D., FATIGATI, F. Fuel economy benefits of a new engine cooling pump based on sliding vane technology with variable eccentricity. ATI 2015 - 70th Conference of the ATI Engineering Association. Energy Procedia. 2015, 82, 265-272.

[4] CIPOLlONE, R., DI BATTISTA, D. Sliding vane rotary pump in engine cooling system for automotive sector. Applied Thermal Engineering. 2015, 76, 157-166.

[5] CIPOLlONE, R., DI BATTISTA, D. Sliding vane rotary pump in engine cooling system for automotive sector. Applied Thermal Engineering. 2015, 76, 157-166.

[6] CIPOLLONE, R., DI BATTISTA, D., CONTALDI, G. et al. Development of a sliding vane rotary pump for engine cooling. 69th Conference of the Italian Thermal Machines Engineering Association. ATI2014. Energy Procedia. 2015, 81, $775-783$.

[7] CIPOllone, R., DI BATtista, D., GUAltiERI, A., MASSIMI, M. Development of thermal modeling in support of engine cooling design. SAE Technical Paper 2013-240090, 2013. DOI: 10.4271/2013-24-0090

[8] FENG, J., LUO, X., BENRA, F.K., DOHMEN, H.J. Experimental investigation of velocity fluctuations in a radial diffuser pump. Journal of Hydrodynamics. 2015, 27(3), 332339. DOI: $10.1016 / \mathrm{S} 1001-6058(15) 60490-5$

[9] FROMM, L., HEROLD, R., KOSZEWNIK, J., REGNER, G. Modernizing the opposed-piston engine for more efficient military ground vehicle applications. Proceedings of the Ground Vehicle Systems Engineering and Technology Symposium. GVSETS 2012.

[10] GRABOWSKI, Ł., PIETRYKOWSKI, K., KARPIŃSKI, P. Energetic analysis of the aircraft diesel engine. MATEC Web of Conferences. 2019, 252, 1-6.

Michał Jan Gęca, DEng. - Faculty of Mechanical Engineering, Lublin University of Technology.

e-mail:m.geca@pollub.pl
[11] HARRIS, N.C., JAHNS, T.M., HUANG, S. Design of an integrated motor/controller drive for an automotive water pump application. Department of Electrical and Computer Engineering University of Wisconsin-Madison Madison. WI 53706, USA.

[12] HEROLD, R.E. et al. Thermodynamic benefits of opposedpiston two-stroke engines. SAE Technical Paper 2011-012216, 2011.

[13] KNEBA, Z. Development trends of automotive engine cooling systems. Combustion Engines. 2013, 154(3), 291296.

[14] KRAKOWSKI, R. Internal combustion engine cooling system with elevated coolant temperature research on the model test stand. Journal of KONES Powertrain and Transport. 2013, 20, 4.

[15] LIM, D.H., KIM, S.C., KIM, M.S. Thermal analysis of an electric water pump for internal combustion engine vehicles. International Journal of Automotive Technology. 2013, 14(4), 579-585. DOI: 10.1007/s12239-013-0062-7

[16] MOHAMED, E.S. Development and analysis of a variable position thermostat for smart cooling system of a light duty diesel vehicles and engine emissions assessment during NEDC. Applied Thermal Engineering. 2016, 99, 358-372.

[17] OGRODZKI, A. Technika cieplna w pojazdach. Wydawnictwo Komunikacji i Łączności. Warszawa 1982.

[18] SALAH, M.H., MITCHELL, T.H., WAGNER, J.R., DAWSON, D.M. A smart multiple-loop automotive cooling. IEEE/ASME Transactions on Mechatronics. 2010, 15(1).

[19] SHIN, Y.H., KIM, S.C., KIM, M.S. Use of electromagnetic clutch water pumps in vehicle engine cooling systems to reduce fuel consumption. Energy. 2013, 57, 624-631.

[20] WANG, X. et al. Comparison of electrical and mechanical water pump performance in internal combustion engine. International Journal of Vehicle Systems Modelling and Testing. 2015, 10(3), 205-223.

[21] www.iparts.pl

\author{
Grzegorz Barański, DEng. - Faculty of Mechanical \\ Engineering, Lublin University of Technology. \\ e-mail: g.baranski@pollub.pl
}

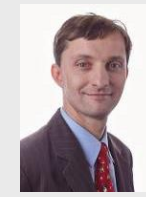

Konrad Pietrykowski, DEng. - Faculty of Mechanical Engineering, Lublin University of Technology. e-mail: k.pietrykowski@pollub.pl 